\title{
La comunicación en vivo: eventos y visibilidad, clave en las organizaciones
}

\author{
Alfredo A. Rodríguez Gómez \\ Universidad Camilo José Cela \\ agomez@ucjc.edu
}

\begin{abstract}
Resumen:
Existe un creciente deseo de las instituciones de comunicar a través de los eventos como forma de acceder a las audiencias de forma directa, en un modelo que engloba técnicas de comunicación, marketing y organización de eventos.

Unir estas técnicas es un sistema muy adecuado de ejercer la comunicación en vivo.

En este trabajo recogemos un análisis sobre el uso de la tecnología actual como herramienta de esa comunicación en vivo y que se utiliza en todas las fases de un evento: la preparación, el evento en sí y el posevento.
\end{abstract}

Palabras clave: Comunicación en vivo; visibilidad; eventos; tecnología; redes sociales.

\section{Live Communication: Events and visibility, key elements for the organizations}

\begin{abstract}
:
There is a growing desire of institutions to communicate through events as a way to directly access the audience, in a model that includes communication skills, marketing and event management. Joining these techniques is therefore a very current exercise for a live communication.

In this paper we report a discussion of the use of current technology as a tool for the live communication, as long as it use in all phases of an event: preparation, event itself and post-event.
\end{abstract}

Key Words: Live communication; visibility; events; tecnology; social networks.

Referencia normalizada:

Rodríguez Gómez, A. A. (2014): La comunicación en vivo: eventos y visibilidad, clave en las organizaciones. Historia y Comunicación Social. Vol. 19. Núm. Especial Enero. Págs. 167-179.

Sumario: 1. Introducción. Metodología. 3. La comunicación del siglo XXI. 4. La evolución de la comunicación. 5. Los eventos del siglo XXI. 6. Redes sociales y eventos: herramientas de visibilidad. 7. El evento como proceso. 7.1. Planeamiento y preparación. 7.2. El evento. 7.3. El posevento. 8. Conclusiones. 9. Referencias bibliográficas.

\section{Introducción}

Internet, en los 90 del pasado siglo, supuso una nueva forma de comunicar que ha cambiado paradigmas. La aparición de un sistema que permitía llevar información desde las organizaciones al usuario aportó un nuevo medio en la relación empre- 
sa-consumidor. Aparecía, para el envío de mensajes y la transmisión de información al público destinatario, un canal, aún monodireccional, pero que abría nuevas posibilidades y recursos.

Pocos años después, la técnica, en continua evolución, trajo una nueva posibilidad de gestión de las redes: la bidireccionalidad. Fue el nacimiento de la web 2.0 y de las redes sociales.

En paralelo, los eventos han eclosionado como forma de las organizaciones de llegar a sus públicos objetivos de una forma rápida y cercana.

Por tanto, existen tres elementos que suponen un pilar de comunicación, en sentido global, al alcance de la mano de las organizaciones para dirigirse a sus mercados: la comunicación, las redes sociales y los eventos; es decir, la comunicación en vivo de las instituciones (Rodríguez Gómez, 2013: 3). Su empleo puede señalar el camino en la comunicación institucional y empresarial del futuro inmediato.

Nos planteamos en este trabajo los siguientes objetivos:

- Establecer la influencia de las redes sociales como elementos de la comunicación en los eventos de hoy, es decir, en los eventos organizados como gestión de imagen de una empresa o institución.

- Determinar la relación entre los eventos y las redes sociales de las organizaciones empresariales e institucionales y su importancia actual.

Cabe reseñar que, a día de hoy, no hemos podido encontrar estudios científicos sobre esta materia, lo que a nuestro juicio hace pertinente este trabajo dado su uso frecuente y avanzado en nuestros días.

\section{Metodología}

Hemos realizado, en primer lugar, una revisión documental sobre los principales aspectos de la comunicación, las redes sociales y los eventos.

Posteriormente, hemos analizado tres eventos de primer nivel: Expomanagement 2012, la presentación del BMW Serie 1 en Madrid Arena y la Mercedes-Benz Fashion Week Madrid, que nos han permitido conocer la forma de utilización de las redes sociales en el evento.

Además, se ha utilizado la observación directa del autor, que cuenta con una amplia experiencia en la organización de eventos institucionales y empresariales.

Establecemos dos soportes para este trabajo: por un lado, las redes sociales como herramientas de comunicación y, por otro, los eventos, también como instrumentos indispensables de la comunicación en el momento actual. 


\section{La comunicación del siglo XXI}

El siglo XXI ha comenzado con una gran evolución tecnológica, tras un siglo XX conocido como siglo de la madurez corporativa en materia de comunicación y en el que se iniciaron procesos de cambio importantes.

Consecuencia de esos cambios fue una modificación de los paradigmas de la comunicación corporativa, cuyo objetivo fundamental es dar a conocer la organización a sus audiencias, transmitiendo una identidad que permita sus públicos tener una buena imagen de la organización.

Para Aced (2013: 35), la comunicación corporativa significa "gestionar la reputación de la organización entre sus públicos". Para ello, siempre según la autora, esa comunicación "se basa en la persuasión".

Es decir, las empresas e instituciones actuales persiguen acercarse a sus grupos de interés mediante acciones de comunicación centradas en cuatro soportes esenciales: la comunicación interna - no cabe hablar de un grupo de mayor interés que los propios empleados - la comunicación externa, las relaciones con los medios de comunicación y la comunicación de crisis.

Algunos autores (Aced, 2013) añaden más pilares: las relaciones institucionales y las públicas; otros (Fuente, 2007; Barriga, 2010; Campos, 2013) los eventos empresariales e institucionales.

Esta comunicación corporativa de nuestros días, de nuestro mundo digital, se basa en gran medida en los beneficios que aportan las redes sociales a la comunicación en general y, en especial, a la corporativa.

Comunicar hoy es, más que nunca, acceder a nuestros públicos de una forma rápida, directa, veraz y completa. Según Rodríguez Gómez (2013b: 80-81), el evento es una herramienta de transmisión de mensajes, información, imágenes y sensaciones, por lo que supone uno de los vehículos imprescindibles para que las acciones estratégicas de imagen alcancen a los destinatarios pertinentes en cada materia específica.

\section{La evolución de la comunicación}

La popularización de Internet supuso una modificación apreciable en esos modelos de comunicación. Como observador participante en ese momento, el autor puede asegurar que la sola posibilidad de intercambiar información en tiempo real y a un coste paulatinamente más económico, garantizó la universalización del acceso a esa información y la hizo asequible a cada día más estratos sociales.

Significó un avance continuo y cuya velocidad se ha multiplicado exponencialmente con el tiempo. Las empresas y las instituciones se lanzaron a partir de ese momento a montar sus escaparates en la telaraña mundial, en un intento de alcanzar 
al ciudadano o al consumidor. De este modo, la comunicación unidireccional entre la marca y el público objetivo abría un nuevo canal que, pronto, sería esencial y cuyos cambios constituirían una revolución.

La consecuente evolución de la técnica renovó el impulso de este canal con la llegada del universo conocido como 2.0 y las implicaciones que este nuevo modelo de Internet tenía en la comunicación. La unidireccionalidad del sistema habitual de comunicaciones establecidas con un emisor, mediante un canal, para acceder a un receptor quedaba trastocada por la facilidad surgida de responder a tal emisor, en el mismo canal o a través de otros, por parte del receptor que, desde ese momento, cambiaba su papel para convertirse a su vez en emisor.

Esta realidad se evidenció también en la comunicación entre empresas y clientes. Las primeras porque encontraron en las redes sociales un escaparate fácil y cada vez más económico, para alcanzar a sus públicos objetivo; los segundos porque tenían canales de respuesta y comunicación directa con las organizaciones.

La comunicación de estas organizaciones ha mostrado en estos años un cambio sustancial. También ha surgido la posibilidad de crear otras acciones de marketing de un producto muy de moda en este momento: los eventos especializados.

Se trata de una pequeña revolución, como apunta Castells (2009), y en la que este nuevo paradigma comunicacional ha cobrado una importante función en la comercialización y marketing de productos e instituciones: la posibilidad de acceder a públicos objetivo de una forma sencilla y directa que se podía trasladar al mundo en general a través de canales de emisión en directo o en diferido, todo ello a un coste muy asequible.

\section{Los eventos del siglo XXI}

El sector de los eventos, y en especial los empresariales aunque también los demás, también ha evolucionado de forma sorprendente y en poco tiempo. De los actos de carácter marcadamente institucional, en los que el boato era parte indispensable y primaba sobre la creatividad y el diseño, y la puesta en escena servía para marcar de forma evidente el poder y primar la diferencia de clases y posiciones, la industria de eventos ha evolucionado de una forma sin precedentes hacia otros modelos con un espíritu distinto, en los que lo que verdaderamente importa es la transmisión de mensajes y sensaciones a los públicos objetivo.

El señalamiento del poder mediante eventos ha dejado, como vemos, de ser clave. Incluso los eventos institucionales prefieren el acercamiento más que la distancia y se sitúan en posiciones corporativas en las que el objetivo esencial es alcanzar a los públicos objetivo mediante acciones directas, segmentadas, a modo de marketing especializado. 
Actualmente es mucho más importante la transmisión de mensajes y la cercanía del ejecutivo empresarial y del directivo institucional sobre cualquier otro tipo de consideración. Es la comunicación en vivo para transmitir señales, mensajes, acordes con nuestros tiempos.

Herrero y Campos (2010: 181) lo matizan de esta forma:

El protocolo se ha convertido en una herramienta estratégica de comunicación de las empresas, tanto a nivel interno y corporativo como en su proyección externa. El protocolo se encuentra también entre una de las posibles acciones estratégicas para reforzar la reputación corporativa. Este trabajo examina cómo los actos comunican, trasladan la imagen y estilo y responsabilidad social corporativa de una organización, permiten la interrelación con los stakeholders y generan experiencia, superando algunas de las acciones tradicionales de comunicación en el ámbito empresarial y/o institucional.

Confirman así que los eventos son una pieza clave en la comunicación de las organizaciones en general.

\section{Redes sociales y eventos: Herramientas de visibilidad}

Aced (Aced et al, 2009: 13) nos deja una reflexión que puede parecer evidente a priori pero que merece nuestra consideración: "Sin visibilidad no hay venta" y establece un parámetro singular: Internet ha puesto al alcance de la mano de cualquiera la posibilidad de ser visible ante los demás sin demasiados problemas ni gastos; en sus palabras, Internet "democratiza la visibilidad" a lo que nosotros añadimos que la red de redes nos acerca la información en tiempo real y de forma fácil y semigratuita.

La ventaja de esta herramienta es que supone una comunicación inmediada y retroactiva; es un depósito de información en donde buscar y recuperar datos y conversaciones a través del tiempo y de la distancia.

Para ello, además, la aparición y el boom de las conocidas como redes sociales, han sido un hito importantísimo al poner al alcance de la mano unas herramientas que permiten hacer de los eventos esa comunicación en vivo que propugnamos.

Lo cierto es que estas tecnologías avanzadas han cambiado los conceptos de comunicación y de eventos para convertirlos en una verdadera interacción entre organizaciones y audiencias en escenarios dispares y en lugares globales.

Según Rodríguez Gómez (2011a), el ciudadano, consumidor de esa comunicación en vivo es ahora un espectador de primera fila y en un evaluador permanente de esos eventos. Señala el autor: "Por tanto, además de ser espectadores 2.0 de nuestros eventos 2.0, lo que nos obliga necesariamente a modificar la forma de organizarlos, también son evaluadores inmediatos de aquello que organizamos" (p. 62). 
Es decir, supone un cambio significativo tanto cualitativo, por la forma, como cuantitativo, por el número de emisores en la organización de los eventos de hoy y del futuro.

Por obra de la técnica y por un sentimiento ciudadano, el espectador de nuestro tiempo ha pasado a ser no ya un mero consumidor sino un evaluador de la actividad $\mathrm{y}$, como tal, un creador de opinión en parte porque las redes sociales, por no hablar de los blogs, son ahora en fuente y canal de información con acceso global.

Algunos, como Espiritusanto (2010), conocen este fenómeno como periodismo ciudadano. En este ámbito en que nos movemos intervienen con asiduidad tanto ciudadanos normales, que expresan su opinión sobre los más diversos temas, como expertos o especialistas en las más diversas materias, que dejan de someterse permanentemente a la revisión de sus productos por terceros y que universalizan su opinión por otras vías en forma de páginas web y de blogs, e incluso a través de las redes sociales.

A todo ello se suma un tercer factor vinculado con los anteriores: la revolución en materia de dispositivos de interconexión como las tabletas o los smartphones. Cisco Systems aporta un estudio ${ }^{1}$ realizado por InsightExpress en 18 países ${ }^{2}$ muy pertinente sobre el uso de los teléfonos por parte de los jóvenes de entre 18 y 30 años, y cuyos resultados son enormemente esclarecedores en cuanto a su necesidad de estar conectados de una forma constante y continua. El estudio, con 3600 encuestados, revela que:

- $\quad$ Nueve de cada diez se visten, cepillan sus dientes, y comprueban sus teléfonos inteligentes como parte de la rutina matutina.

- Un 29 por ciento dice comprobar sus teléfonos un incontable número de veces a lo largo del día.

- Uno de cada cinco revisa su teléfono para ver el correo electrónico, textos y actualizaciones de redes sociales al menos cada 10 minutos.

- Un tercio mira su teléfono al menos una vez cada 30 minutos.

- $\quad$ El 60 por ciento mira compulsivamente sus teléfonos para ver correos electrónicos, textos o actualizaciones de redes sociales.

- Las mujeres se sienten más impulsadas a conectarse: el 85 por ciento, frente al 63 de los hombres, mira compulsivamente sus teléfonos para hacer comprobaciones frecuentes.

- Más del 40 por ciento de los encuestados se sentiría ansioso si no pudiera revisar su teléfono constantemente.

- Tres de cada cuatro utilizan los teléfonos en la cama.

- Más de un tercio usa el teléfono en el cuarto de baño. 
- Un 46 por ciento envía textos, ve correos electrónicos y comprueba las redes sociales en las comidas con familia y amigos.

- Uno de cada cinco envía textos mientras conduce.

- El 40 por ciento pasa más tiempo con amigos en línea que en persona.

- El 87 por ciento tiene una cuenta de Facebook y uno de cada 10 la tiene siempre abierta.

- El 41 por ciento actualiza Facebook al menos una vez al día, y uno de cada cinco lo hace varias veces al día.

- El 56 por ciento de los encuestados tiene una cuenta de Twitter y el 21 por ciento envía mensajes por esta red al menos una vez al día.

Son cifras reveladoras de una realidad que influye en el mercado de eventos: la capacidad de conexión que llevamos la mayoría en los bolsillos gracias a las tabletas y teléfonos inteligentes. También nos marcan un rumbo nuevo en materia de comunicación cuya fuerza potencial aumenta exponencialmente las posibilidades de comunicación en los eventos.

\section{El evento como proceso}

Como señalábamos, el evento ha dejado de ser una mera representación plástica del poder para convertirse en uno de los modelos de comunicación más importantes en la actualidad, ya que cumple los requisitos de las organizaciones hoy.

Las empresas necesitan ir un paso por delante en la publicidad y el marketing de sus productos y de las propias organizaciones porque el consumidor, a su vez, demanda otras cosas antes de adquirir un bien o servicio que el tradicional anuncio publicitario no puede dar: quiere saber qué opinan otros consumidores $-\mathrm{y}$ en eso intervienen las redes sociales, que en cierta medida toman el relevo de los foros especializados-y quieren sentir el producto; necesitan llenarse de sensaciones más allá de lo que diga la propia empresa.

El motivo es que la publicidad tradicional en prensa, radio o televisión pierde en gran medida su eficacia en buena parte por ese mismo avance de la técnica que habilita al espectador para obtener información a la carta de forma inmediata, pero también porque los consumidores ya no se fían tanto de lo que diga la empresa de sus propios productos como de lo que opinen de ellos otros consumidores y, a tal fin informativo, nada más oportuno que las redes sociales.

Además, si añadimos la experiencia de las sensaciones que produce la comunicación en vivo, la que se obtiene con los eventos, el acercamiento a las audiencias es pleno y el objetivo se cumplirá también plenamente. 
Por ese motivo el evento ha cobrado tanta importancia: porque transmite esas sensaciones que las empresas y organizaciones en general quieren hacer vivir a sus públicos objetivo. Y, además, lo puede hacer yendo más allá del espacio físico del evento.

La capacidad de traspasar las paredes, ficticias o reales, de un recinto para llevar las experiencias a una audiencia a la vez universal y segmentada es lo que produce el efecto positivo de esta nueva forma de comunicación.

Como decimos, la aportación que las redes sociales hacen a este campo, el de la comunicación en eventos, es de enorme importancia. Si bien hay una carencia de estudios científicos sobre el particular, lo que justifica de por sí este artículo, empieza a haber otros de carácter divulgativo que, a falta de los primeros, se convierten en relevantes, ya que son fiel reflejo de las experiencias del sector.

Asimismo, es necesario evaluar el propio sector para comprobar cómo se emplean las redes sociales en la organización de los eventos.

Simplificando el proceso de un evento para facilitar su estudio, establecemos tres fases: planeamiento y preparación, evento y posevento - fase previa, evento en sí mismo y recogida de resultados, seguimiento y evaluación-. De la observación directa del autor, del estudio del material divulgativo señalado en la bibliografía y del análisis de tres eventos: Expomanagement 2012, la presentación del BMW Serie 1 y la Mercedes-Benz Fashion Week Madrid, es decir, eventos de categorías diferentes, con distintos públicos objetivo y modos de producción, podemos extraer las siguientes formas de empleo de estas redes sociales en las tres fases antedichas.

Estamos convencidos de que la tecnología debe emplearse para transmitir esas sensaciones mencionadas sobradamente en este artículo y que están en creciente demanda por parte de las audiencias, lo que implica aumentar su participación en todas las fases del proceso; ello supone enriquecer su experiencia y captar y transmitir correctamente sus mensajes.

A su vez, como valor añadido, esas audiencias pueden formar parte del evento en sí en las tres fases citadas con una participación activa en el fomento previo, en la implicación durante el desarrollo y en los comentarios posteriores para el análisis posterior a la ejecución del evento.

Para Universal Worldevents (2013): ${ }^{3}$

La web del evento y las apps son herramientas vitales hoy, y tienen un papel clave en el proceso de comunicación. Cuanto más puedes implicar a tu público en el pre-evento, mejor. Por ejemplo, pídeles que graben y suban un vídeo sobre un tema que quieran compartir y mira si consiguen ser difundidos y comentados. Y el presentador puede utilizar esta información para definir y enriquecer el contenido, sabiendo qué tipo de información desean tener los invitados. (p. 16)

Lo que supone el uso de la tecnología es el aumento de la implicación del público en todas las fases del evento; en una fase previa para implicarlo y fomentar el deseo de asistir, la necesidad de vivir esa experiencia. Durante la ejecución, para implicar al 
público en la actividad del evento. En la tercera, tras terminar la arte más visible del acto, como repositorio de material textual y audiovisual, y para recoger sus comentarios y detectar áreas de éxito y áreas de mejora.

Del análisis de los eventos y de la observación directa podemos deducir que el empleo de las redes sociales en las tres mencionadas fases es la siguiente:

\subsection{Planteamiento y preparación}

Una de las principales funciones que se realizan en la fase previa de un evento es la comunicación. Más allá de que determinados usos de las redes sociales pueden servir para establecer un buen canal de comunicación interna, si lo que se desea es crear expectativas y dar a conocer un futuro evento, estas redes cumplen el objetivo.

También sirven como herramientas de colaboración en un equipo de organización que lo mantendrá al corriente de los trabajos de todos con todos; es una parte de esa comunicación interna que apuntábamos.

Generar expectativas fue piedra común en los tres eventos seleccionados que, cada uno en su tipo, comunicó a través de estas redes las novedades y cuanta información se consideró pertinente, tanto en el caso de Expomanagement y la semana de la moda, como la comunicación, además, de las posibilidades del vehículo en el tercer caso.

La viralización, en los tres estudios, logró el efecto deseado y convirtieron a cada uno de ellos en noticia entre los distintos públicos objetivo.

La experiencia y el estudio de casos nos indican que, si se pretende dar a conocer el evento, una adecuada combinación de herramientas sociales contribuirá a ello de forma muy eficaz.

Desde las posibilidades de extensión pública, por el boca a boca, de un vídeo a través de Youtube, Vimeo o similar, hasta proporcionar la información del evento de forma más pertinente y detallada mediante una web o un microsite específico, un blog o herramientas como Facebook o Google+, todo apoyado en Twitter como forma de trasladar la información a un buen número de seguidores.

Los instrumentos actuales son muy útiles para llegar a la audiencia y conectar con ella; es decir, para construir una expectativa, y hacer que la audiencia se implique en el evento en esta etapa de preparación en la que nada tiene tanto éxito como alcanzar una plena conexión con esa audiencia cada vez más exigente.

\subsection{El evento}

Si en la fase analizada son importantes las redes sociales y modifican la forma de comunicar, durante la ejecución juegan una función que puede llegar a ser vital para sumergir a las audiencias en todos los aspectos del acto.

En los eventos que hemos estudiado y que hemos señalado para este trabajo, el público pudo participar de forma directa en cada uno de los momentos de la ejecu- 
ción. En Expomanagement, a través de comentarios y preguntas a los ponentes lanzados con su propio hashtag que se hacen universales al emitirse en Twitter.

También en los otros dos eventos con comentarios, envío de fotos y vídeos, haciendo que se convirtieran en tema de discusión prioritario a nivel nacional. Y, desde luego, unos y otros, gracias a la transmisión de vídeo en directo.

Según Terzagui (2013), para Mariano Peres,${ }^{4}$ la mejor opción en la ejecución es la sincronización de las redes sociales de modo que lo que en ellas se publica dirija a las audiencias a la web oficial.

También es recomendable el uso de redes como Twitter como canal de interactuación, con conversaciones en directo en pantalla —o backchannel-, además de emplear las fuentes de vídeo para transmisión en directo, lo que permite globalizar las acciones.

\subsection{El postevento}

El evento no acaba al finalizar el acto en sí; una vez termina se inicia una una fase de la que debemos sacar ventaja para consolidar lo realizado y materializar la consolidación de lo sucedido en una serie de acciones que permitan revivirlo tiempo después y sacar provecho de él a lo largo del tiempo. Material multimedia o gráfico, tanto como comentarios y textos de distintos tipos — ponencias, mensajes recibidos, etc.- , son un valioso bagaje que permitirá consolidar el producto más allá de la fecha de mera ejecución.

Además, el seguimiento que haya tenido el evento y los comentarios o clics en los clásicos "Me gusta" servirán para hacerse una idea del retorno, en materia de comunicación, de nuestras acciones, lo que nos permitirá en el futuro mejorar resultados y alcanzar la mayor difusión posible de los eventos.

Los actos analizados siguen estas técnicas y, tras la ejecución, se pueden consultar fotografías y vídeos, así como acceder a textos que mantienen vivo el acto para las audiencias que en su día asistieron, tanto como para su uso en diferido, haciendo que perdure en el tiempo y que siga teniendo visitas meses después de realizado. Además, los organizadores mantienen el contacto con los asistentes para recibir sus comentarios y áreas de mejora.

\section{Conclusiones}

Los eventos son una de las formas de las organizaciones para alcanzar una buena repercusión en los medios y entre ellos se encuentran las redes sociales, que sirven de soporte al llamado periodismo ciudadano. El nuevo escenario de los eventos implica pensar en estas redes si se desea universalizar la información. 
Las empresas deben optimizar el uso de las redes sociales en eventos y aprovechar las ventajas que ofrecen. Esas herramientas son una forma diferente de comunicar que los convierten en parte del proceso creativo por el que, con mucho acierto y buen criterio, aboga Campos (2013) y que sirve a las tres fases del proceso, con ventajas inherentes como una mayor capacidad de convocatoria, mejor y más amplia visibilidad y alcance, potencialidad viral, capacidad ilimitada de interacción con las audiencias, generación de comunidad y capacidad de retorno inmediato.

Hoy no se puede obviar a las audiencias al planificar un evento pero tampoco a las redes sociales, que posibilitan a esos públicos contribuir a prepararlo, vivirlo en directo o en diferido desde cualquier lugar del mundo, de forma activa o pasiva y en un escenario que hoy ya es universal.

De este modo, las marcas pueden dirigirse a las audiencias de modo directo y, además, escucharlas a través de un diálogo que se produce en tiempo real y sin intermediarios que distorsionen los respectivos mensajes, lo que reduce el ruido de esas transmisiones y les confiere el atributo de bidireccionalidad plena.

Ello nos exige crear una experiencia coordinada tanto en línea como sin conexión, con información y formatos preconcebidos de forma específica para los medios que van a servir de canal de transmisión en cada caso, atendiendo a las especificidades de cada uno de ellos.

Además, fomenta una nueva exigencia: la inclusión de estos canales en los planes de estudios de los grados que hoy imparten la organización de eventos como formación universitaria.

Con ello, consideramos cumplidos los objetivos que nos proponíamos, a saber: hemos dejado establecida la importante influencia de las redes sociales como elementos de la comunicación en los eventos de hoy y hemos determinado la estrecha relación entre eventos y redes sociales de las organizaciones y su importancia en nuestros días.

\section{Bibliografía}

ACED, C. (2013). Relaciones Públicas 2.0. Cómo gestionar la comunicación corporativa en el entorno digital. Barcelona: UOC.

ACED, C.; SANAGUSTÍN, E.; LLODRA, B. (2009). Visibilidad. Cómo gestionar la reputación en Internet. Barcelona: Gestión 2000.

BARRIGA, A. (2010). La creatividad en los eventos. Madrid: Ediciones Protocolo.

CASTELLS, M. (2009). Comunicación y poder. Madrid: Alianza Editorial.

CAMPOS, G. (2013). El proceso de creatividad en los eventos de empresa. En Compé, Revista Científica de Comunicación, Protocolo y Eventos no 1, pp. 21-36. Disponible en: http://compe.es/Articulos/Compe1_21-36.pdf [10-09-2013]. 
ESPIRITUSANTO, O. (2010). Periodismo ciudadano: el fenómeno mojo. Telos: cuadernos de comunicación e innovación, (83), 100-103.

HERRERO, J.C.; y CAMPOS, G. (2010). "El necesario protocolo en la comunicación organizacional". En Icono 14, 2, pp. 181-202. Disponible en: http://www. icono14.net/ojs/index.php/icono14/article/view/252. Consultado el 1 de septiembre de 2013.

FUENTE, C. (2007). Protocolo para eventos. Madrid: Ediciones Protocolo.

MARX, D. A. (2011). ¿Hacia dónde va Túnez? La Revolución de los Jazmines, aún lejos de terminar. Cuadernos Manuel Jiménez Abad (1), 1-9. Disponible en: www. Dialnet-HaciaDondeVaTunezLaRevolucionDeLosJazminesAunLejos-4047757. [18-09-2013].

MOLINA, J.P. (2011). Introducción a la comunicación institucional a través de Internet. Madrid: Editorial Grupo 5.

MOROZOV, E. (2011). El desengaño de internet. Barcelona: Ediciones Destino, S.A. RODRÍGUEZ GÓMEZ, A. (2011a). Cómo organizar un evento 2.0 en Revista Protocolo (57), pp. 48-53.

(2011b). "Eventos 2.0, el futuro ha llegado". En Revista Protocolo $\mathrm{n}^{\circ}$ 58, pp. 62-65.

(2011c). "Protocolo 2.0, ¿ficción o realidad?". En Revista Protocolo (59) (pp. 65-70).

(2013). Comunicación en vivo: En Compé, Revista Científica de Comunicación, Protocolo y Eventos, p. 1. Disponible en: http://compe.es/Articulos/Compe1_-3. pdf. [5-09-2013].

TERZAGUI, L.( 2013). "Eventos y redes sociales: consejos para el éxito". En Eventos magazine (46) (pp. 68-69).

UNIVERSAL WORLDEVENTS. (2013). "Engagement: conseguir el compromiso del target". En Eventos Magazine (46), p. 16.

\section{Notas}

1. Fuente: Dinero.com: http://www.dinero.com/empresas/tecnologia/articulo/20-cifras-curiosas-sobre-uso-smartphones/168618 [20-06-2013].

2. Estados Unidos, Canadá, México, Brasil, Argentina, Reino Unido, Francia, Alemania, Holanda, Rusia, Polonia, Turquía, Sudáfrica, India, China, Japón, Corea del Sur y Australia.

3. Empresa de eventos.

4. Socio y director creativo ejecutivo de Go Next. 


\section{El autor}

Profesor de la UCJC en grado y tres másteres oficiales. DEA en Derecho Internacional Público y Relaciones Internacionales. Doctorando por la UCM con la tesis "Diplomacia pública española desde 1939 a 2012. Comunicación, imagen y marca España" (depositada; prevista lectura en enero de 2014). Máster en Comunicación Social por la UCM. Profesor invitado en programas máster de las universidades de Salamanca, Católica de Murcia, Carlos III, Complutense de Madrid, Antonio Nebrija y George Washington. Miembro de la Asociación Científica Icono 14 e investigador en dos programas de investigación de la UCJC. Director y editor de Compé, Revista Científica de Comunicación, Protocolo y Eventos. 